\title{
Bronchodilator effects of antiasthmatic cigarette smoke (Datura stramonium)
}

\author{
D CHARPIN, J OREHEK, AND J M VELARDOCCHIO
}

\begin{abstract}
From the Laboratoire d'Exploration Fonctionnelle Respiratoire de l'hôpital Salvator and Inserm U 74, Marseille, France
\end{abstract}

ABSTRACT In 12 asthmatic patients with mild airway obstruction we have measured the effect on specific airway resistance (sRaw) of inhaling the smoke of one Datura stramonium cigarette. In 11 patients sRaw decreased substantially after the cigarette, the mean maximal decrease being $40 \%$ at the 30th minute. In seven patients the subsequent inhalation of $200 \mu \mathrm{g}$ salbutamol caused no further decrease in sRaw. In the remaining four patients salbutamol induced a larger decrease in sRaw than the cigarette smoke. The inhalation, however, of a synthetic anticholinergic agent (SCH 1000, $600 \mu \mathrm{g}$ ) proved as effective as salbutamol in these patients. In one patient the cigarette smoke and $\mathrm{SCH} 1000$ produced only a negligible amount of bronchodilatation whereas the bronchial obstruction was reversible with salbutamol. Minor side effects were observed in six patients after the cigarette.

In recent years the interest in anticholinergic drugs for the treatment of asthma has been revived but the use of such drugs can be traced back to antiquity (Gandevia, 1975). Anticholinergic preparations made from various plant materials (asthma cigarettes and smoke powders) were widely used in the nineteenth century but the lack of suitable techniques precluded their objective assessment at that time. When modern lung function testing became available these medications had already been made obsolete by the introduction of the adrenergic agonists in the 'thirties. This probably explains why respiratory physiologists have paid very little attention to antiasthmatic cigarettes. Apparently only two published studies have been devoted to the antiasthmatic cigarette (Herxheimer, 1959; Trechsel et al, 1973), but none have compared its effect to that of modern beta-adrenergic agonists. This observation added to the fact that antiasthmatic cigarettes are still used by a fairly large number of patients with asthma (four brands of antiasthmatic cigarettes are presently sold in France) has prompted us to study the comparative effects of Datura stramonium cigarette smoke and salbutamol in 12 patients with asthma.

\section{Methods}

Twelve patients (mean age $\pm S E$ : $41 \pm 3$ years; 10 men) with extrinsic or intrinsic asthma were studied. Eleven were inpatients. Three were tobacco cigarette smokers (from 10 to 20 cigarettes a day). They refrained from taking their usual medications (steroids or adrenergic bronchodilators or both) for at least 18 hours before the test. All gave fully informed consent to the studies.

Specific airway resistance (sRaw) was measured with a body plethysmograph and the panting technique (Dubois et al, 1956). In all cases the value of sRaw was higher than normal. Heart rate (HR) was counted at the radial artery. After the initial measurement of sRaw and HR, the subject was instructed to inhale deeply the smoke of a cigarette (Cigarette Legras, laboratoires Berthiot) containing Datura stramonium leaves (table 1).

To avoid the possible effect of suggestion the subjects were told only that cigarette smoking could make their breathing better, worse, or unchanged. They had never used antiasthmatic cigarettes before. The number of puffs inhaled

Table 1 Composition of one antiasthmatic cigarette

\begin{tabular}{ll}
\hline & $g$ \\
\hline Leaves and extract of Datura stramonium & 0.774 \\
Resin of gum benzoin & 0.009 \\
Potassium nitrate & 0.108 \\
Plant vehicle & 0.009 \\
\hline
\end{tabular}


(mean number \pm SE: $11 \cdot 5 \pm 1 \cdot 5$ ) and the duration of smoking (mean duration $\pm \mathrm{SE}$ : $5 \mathrm{~min} \pm 30 \mathrm{~s}$ ) were recorded, and the subjects were observed for coughing or any subjective side effects.

SRaw and HR were measured every 10 minutes for one hour. Two puffs $(200 \mu \mathrm{g})$ of a metered adrenergic aerosol (salbutamol) were then administered and the measurements repeated after a 10minute interval (test 1). Patients in whom the maximal decrease in sRaw after anticholinergic cigarette smoking was less than that observed after salbutamol were re-examined one or two days later (test 2). If the initial values of sRaw were similar to those observed on test 1 , the subjects inhaled six puffs $(600 \mu \mathrm{g})$ of a metered anticholinergic aerosol (SCH 1000, Boehringer Ingelheim) and sRaw and HR were measured 10 minutes afterwards. Salbutamol $(200 \mu \mathrm{g})$ was then inhaled and the measurements repeated after another 10minute wait.

\section{Results}

In 11 subjects the inhalation of the smoke of a $D$ stramonium cigarette caused a substantial decrease of initial sRaw ranging from $25 \%$ to $70 \%$ at the time of maximal bronchodilatation. The magnitude of the mean change and its time course are shown in the figure. The mean maximal decrease of sRaw $(40 \%)$ occurred at 30 minutes but all the sRaw measurements after the cigarette were significantly less than the initial values ( $P<0.001$ with Student's paired $t$ test). At the 60th minute, the sRaw value tended to return to its baseline level and was significantly higher $(P<0.01)$ than the lowest value observed.

In seven patients the decrease in sRaw after salbutamol was less than $10 \%$ of the lowest sRaw value observed after the cigarette, but in four patients salbutamol caused a decrease in sRaw amounting to more than $20 \%$ of the lowest sRaw

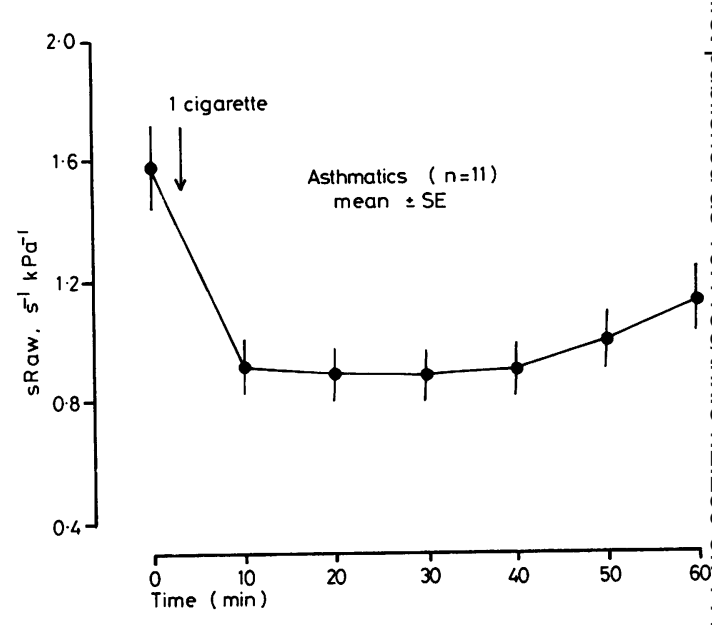

Effect of inhalation of smoke of one antiasthmatic (Datura stramonium) cigarette on specific airway resistance ( $s$ Raw). Time zero corresponds to end of smoking period.

value obtained (table 2). When the latter grous inhaled SCH 1000 (test 2), however, the decrease in sRaw was not significantly different from that induced by salbutamol (table 2).

In one subject the inhalation of both $D$ strats monium cigareite smoke and $\mathrm{SCH} 1000$ cause $\bar{\Phi}$ only a minor change in sRaw (decrease from 1.8. to $1.7 \mathrm{kPa}$ sec on test 1 and from 2.6 to $2.3 \mathrm{kP}$ $\mathrm{sec}$ on test 2) while the subsequent inhalation of salbutamol brought sRaw close to the norma range $(0.8 \mathrm{kPa} \sec$ on test 1 and $0.7 \mathrm{kPa} \sec$ or test 2). Based on clinical criteria, this subject dig not appear to be different from the rest of the group.

For the whole group of 12 subjects we observed no change in HR. The only side effects observed were moderate (four patients) or intense (on patient) coughing and slight degree of chest tighte.

Table 2 Comparative effect of Datura stramonium cigarette smoke, salbutamol, and SCH 1000 on sRaw in 11 asthmatic patients. Statistical calculations were done with Student's paired t test

\begin{tabular}{|c|c|c|c|c|c|c|}
\hline \multirow[t]{2}{*}{ Patients* } & \multirow[t]{2}{*}{ Test $\dagger$} & \multicolumn{5}{|c|}{ sRaw $(k P a$ sec, mean $\pm S E) \ddagger$} \\
\hline & & Control & & $\begin{array}{l}\text { After } \\
\text { anticholinergic } \\
\text { aerosol }\end{array}$ & & $\begin{array}{l}\text { After salbutamol } \\
\text { aerosol }\end{array}$ \\
\hline $\mathrm{n}=7$ & 1 & $1 \cdot 39 \pm 0 \cdot 15$ & $P<0.01$ & $0.69 \pm 0.09$ & NS & $0.71 \pm 0.09$ \\
\hline \multirow[t]{2}{*}{$\mathrm{n}=4$} & 1 & $1.91 \pm 0.24$ & $P<0.05$ & $1.02 \pm 0.08$ & $P<0.05$ & $0.63 \pm 0.04$ \\
\hline & 2 & $1 \cdot 87 \pm 0 \cdot 19$ & $P<0.05$ & $0.75 \pm 0.02$ & NS & $0.67 \pm 0.03$ \\
\hline
\end{tabular}


ness and headache (one patient). Six patients did not inhale the smoke deeply. The four subjects in whom the bronchodilator effect of the cigarette was of lesser magnitude than that of salbutamol were among them.

\section{Discussion}

According to Muir (1972), cigarette smoke constitutes an aerosol capable of reaching all parts of the bronchial tree. Indeed, our study shows that the smoke of an antiasthmatic cigarette is an effective bronchodilator in asthmatic patients with mild airways obstruction. Since the major component of the cigarette tested is $D$ stramonium, the bronchodilatation was probably mediated through the inhibition of cholinergic airway smooth muscle tone. On the other hand, the bronchodilator effect that we observed could have been partly due to the release of nitrite from potassium nitrate. The dose of nitrite released, however, was probably small. Furthermore, if nitrite contained in the smoke had been effective, bronchodilatation would probably have occurred in the one subject insensitive to the action of the cigarette and of $\mathrm{SCH} 1000$ since nitrite is known to relax the smooth muscle directly (Nickerson, 1965).

The maximal bronchodilator effect of the cigarette tested was similar in most patients to that of a modern adrenergic drug, salbutamol. This observation is in keeping with reported data concerning $\mathrm{SCH} 1000$, a synthetic anticholinergic aerosol (Böhning and Fabel, 1975). The lesser effect observed in some patients was probably due to poor inhalation of the smoke rather than to a relative ineffectiveness of cholinergic inhibitors, since in these patients $\mathrm{SCH} 1000$ was as active as salbutamol.

One patient, however, did not respond either to $D$ stramonium or to $\mathrm{SCH} 1000$ whereas he was sensitive to salbutamol. This suggests that noncholinergic bronchoconstrictor mechanism was responsible for his increased airway tone. Moreover, this observation points out the necessity to assess objectively the effect of a given bronchodilator drug in a given patient before prescribing it.

Few side effects could be attributed to the antiasthmatic cigarette smoke in our study. Inhalation of the smoke was adequate in half the cases, and this contrasts with the observation that $75 \%$ of asthmatic patients are unable to inhale the modern cannister aerosols correctly (Orehek et al, 1976). The regular use of antiasthmatic cigarettes, how- ever, cannot be recommended for the following reasons: (1) the duration of action seems rather short, probably less than that of the $\beta_{2}$-adrenergic drugs (Gayrard et al, 1970) or SCH 1000 (Maesen and Buytendijk, 1975). This could therefore lead to repeated inhalations and tachyphylaxis might occur. The risk of addiction from overuse has also been suggested (Gandevia, 1975); (2) the total composition of the smoke is not known. It may contain unwanted alkaloids, particles that may cause chronic mucosal inflammation, or even carcinogenic agents.

\section{References}

Böhning, W, Fabel, M (1975). Comparison of the onset of action of SCH 1000 and orciprenaline given by metered dose inhaler. (Abstract 2/1). Postgraduate Medical Journal, suppl 7, 51, 95-100.

Dubois, A B, Bothelho, S Y, Comroe, J M (1956). A new method for measuring airway resistance in man using a body plethysmograph. Journal of Clinical Investigation, 35, 327-335.

Gandevia, B (1975). Historical review of the use of parasympatholytic agents in the treatment of respiratory disorders. Postgraduate Medical Journal, suppl 7, 51, 13-20.

Gayrard, P, Orehek, J, and Charpin, J (1970). Effects comparés d'un nouveau stimulant béta-adrénergique dans l'asthme. La Presse Médicale, 78, 2337-2338.

Herxheimer, H (1959). Atropine cigarettes in asthma and emphysema. British Medical Journal, 2, 167171.

Maesen, F, Buytendijk, I (1975). Dose and time response curves of $\mathrm{SCH} 1000$ and placebo. Differential response in asthmatics and bronchitics as measured by $\mathrm{FEV}_{1.0}$, vital capacity, blood pressure and heart rate (Abstract 2/8). Postgraduate Medical Journal, suppl 7, 51, 97.

Muir, D C F (1972). In Clinical Aspects of Inhaled Particles, edited by D C F Muir, pp 185-190. Heinemann, London.

Nickerson, M (1965). Vasodilator drugs. In The Pharmacological Basis of Therapeutics. Edited by L S Goodman and A Gilman, 3rd edition, pp 736753. Macmillan, New York.

Orehek, J, Gayrard, P, Grimaud, C, Charpin, J (1976). Patient error in use of bronchodilator metered aerosols. British Medical Journal, 1, 76-77.

Trechsel, K, Bachofen, H, and Scherrer, M (1973). Die bronchodilatorische Wirkung der Asthmazigarette. Schweizerische Medizinische Wochenschrift, 103, 415-418.

Requests for reprints to: Dr J Orehek, Hôpital Salvator, Laboratoire d'Exploration Fonctionnelle Respiratoire, 249 chemin de Sainte-Marguerite, Marseille. 